\title{
Synthesis of pyridyl carbyne complexes and their conversion to $\mathbf{N}$ - heterocyclic vinylidenes
}

\author{
Benjamin J. Frogley and Anthony F. Hill ${ }^{\mathrm{a}, *}$
}

\begin{abstract}
A new synthetic approach to hetero-aryl substituted carbyne complexes has allowed the synthesis of pyridyl functionalised carbynes and bis(carbynes), alkylation of which affords the first $\boldsymbol{N}$-heterocyclic vinylidene complexes.

The vast majority of simple aryl-substituted carbyne complexes are available via either Fischer's seminal oxide/alkoxideabstraction routes ${ }^{1}$ or Schrock's $\alpha$-metal-hydride elimination ${ }^{2}$ or alkyne scission/metathesis ${ }^{3}$ protocols. Given the centrality of carbynes to alkyne metathesis processes, it is not surprising that the major focus has been on carbynes with hydrocarbon substituents. ${ }^{4}$ Our own interest in carbyne complexes has been concerned with employing the metal-carbon multiple bond as a 'solder' for connecting metal centres via electronically conductive bridging ligands, ${ }^{5}$ within the broader context of socalled molecular wires. ${ }^{6}$ One such approach, explored by Hopkins, has involved incorporating 4-pyridyl groups. ${ }^{7}$ An oligomeric 4-lutidinylcarbyne complex was obtained via scission of 4-butynyl lutidine (Chart 1a) while coupling of a 4-ethynyl benzylidyne with 4-bromopyridine allowed late introduction of a pyridyl group (Chart 1b). Finally, a phenanthroline substituted carbyne complex (Chart 1c) was recently isolated from the direct attack of a lithiocarbyne on a platinum coordinated phenanthroline ligand. ${ }^{8}$ The formation of this last example is specific to the platinum precursor and accordingly, we have entertained the possibility of preparing uncoordinated pyridylfunctionalised carbynes via a synthetic approach that might offer more generality. The Fischer route is inappropriate because it involves treating an acylate or alkoxycarbene with strong Lewis acids (e.g., $\mathrm{BBr}_{3},\left[\mathrm{Me}_{3} \mathrm{O}\right] \mathrm{BF}_{4},\left(\mathrm{CF}_{3} \mathrm{CO}\right)_{2} \mathrm{O}, \mathrm{O}_{2} \mathrm{C}_{2} \mathrm{Cl}_{2}$, $\mathrm{OSCl}_{2}$ etc.) that are incompatible with a pyridyl group. Similarly,
\end{abstract}

\footnotetext{
a. Research School of Chemistry, Australian National University, Canberra,

Australian Capital Territory, ACT 2601, Australia.

* Corresponding author. E-mail: a.hill@anu.edu.au

CCDC 1955818-1955824 contain the supplementary crystallographic data for this paper and are available free of charge from The Cambridge Crystallographic Data Centre.
}



Chart 1. Pyridyl or phenanthroline functionalised carbynes.

$\alpha$-elimination strategies call for coordinatively unsaturated metal centres that are typically deactivated by pyridine coordination. We report herein a new method for the preparation of (hetero)aryl carbynes, illustrating the protocol with the synthesis of mono- and bis(carbyne)functionalised pyridines, which themselves provide access to the first examples of $\mathrm{N}$-heterocyclic vinylidene complexes.

Heating the stannylcarbyne complex $\left[\mathrm{W}\left(\equiv \mathrm{CSn}^{n} \mathrm{Bu}_{3}\right)(\mathrm{CO})_{2}\left(\mathrm{Tp}^{*}\right)\right](\mathbf{1})^{9,10}$ with 2-bromopyridine in the presence of $\left[\mathrm{Pd}\left(\mathrm{PPh}_{3}\right)_{4}\right]$ and $\left[\mathrm{AuCl}\left(\mathrm{SMe}_{2}\right)\right]$ in toluene provides the 2-pyridylcarbyne $\left[\mathrm{NC}_{5} \mathrm{H}_{4}\left\{\mathrm{C} \equiv \mathrm{W}(\mathrm{CO})_{2}\left(\mathrm{Tp}^{*}\right)\right\}\right.$-2] (2, Scheme 1, Figure 1$)$ in good yield $(71 \%$, Scheme 1$)$. Notably, no reaction occurs at all in the absence of the gold(I) additive from which it may be inferred that transmetallation from tin to gold must occur en route to $\mathrm{Pd}(\mathrm{II})$. Indeed, reaction of 1 with $\left[\mathrm{AuCl}\left(\mathrm{SMe}_{2}\right)\right.$ ] alone gives the octametallic carbido ring $\left[\mathrm{W}(\equiv \mathrm{CAu})(\mathrm{CO})_{2}\left(\mathrm{Tp}^{*}\right)\right]_{4} \cdot{ }^{9 a}$ The role of the gold $(\mathrm{I})$ additive is reminiscent of the "copper effect," whereby a copper(I) additive significantly increases the rate of traditional Stille coupling reactions. ${ }^{11} \mathrm{~A}$ comparable effect with gold(I) co-catalysts has also been noted recently and has been found especially useful for the coupling of bulky groups which are otherwise unreactive under conventional Stille coupling conditions. ${ }^{12}$ This protocol is not limited to monosubstitution such that the reaction of 1 with half an equivalent of 2,6-dibromopyridine with the same catalyst loadings furnishes the 2,6bis(carbyne)pyridine complex $\left[\mathrm{NC}_{5} \mathrm{H}_{3}\left\{\mathrm{C} \equiv \mathrm{W}(\mathrm{CO})_{2}\left(\mathrm{Tp}^{*}\right)\right\}_{2}-2,6\right]$ 


$$
\mathrm{OC}_{\mathrm{OC}}^{\mathrm{W}}=\mathrm{C}-\mathrm{Sn}^{n} \mathrm{Bu}_{3} \frac{\mathrm{Nol \% [ \textrm {Pd } ( \mathrm { PPh } _ { 3 } ) _ { 4 } ]}}{10 \mathrm{~mol} \%\left[\mathrm{AuCl}(\mathrm{SMe})_{2}\right]}
$$<smiles>CCC[N+]([O-])([O-])C#Cc1ccccn1</smiles>

(2) $71 \%$
Scheme 1. Synthesis of pyridyl-substituted carbynes via $\mathrm{Pd}(0) / \mathrm{Au}(\mathrm{I})$-catalysed crosscoupling reactions.

(3, Scheme 1). Longer reaction times (14 hours, toluene reflux) and reduced $45 \%$ yield presumably reflect the unfavorable steric congestion attending close proximity of the bulky Tp* ligands. Selected spectroscopic and structural data for 2, $\mathbf{3}$ and all other new compounds reported herein are presented in Table 1.

\begin{tabular}{|c|c|c|c|c|c|}
\hline & $\delta_{\equiv C^{a}}$ & ${ }^{1} J_{C W}{ }^{b}$ & $r_{W} \equiv C^{c}$ & $\angle \mathrm{w} \equiv \mathrm{C}-\mathrm{C}^{\mathrm{d}}$ & $v_{\mathrm{CO}}{ }^{e}$ \\
\hline 2 & 275.9 & 190 & $1.810(7)$ & $167.8(7)$ & 1981,1889 \\
\hline 3 & 276.7 & 191 & & & 1980,1890 \\
\hline$[4]^{+}$ & 260.3 & $-f$ & & & 2010,1924 \\
\hline$[5]^{+}$ & 251.5 & $-f$ & $1.843(7)$ & $168.9(6)$ & 2010,1925 \\
\hline$[6]^{+}$ & 251.5 & 190 & $1.820(3)$ & $173.9(3)$ & 2009,1922 \\
\hline$[7]^{+}$ & 251.9 & 199 & $\begin{array}{l}1.810(11) \\
1.820(11)\end{array}$ & $\begin{array}{l}175.3(9) \\
169.1(9)\end{array}$ & 2006, 1923 \\
\hline 8 & 262.1 & $-f$ & $1.929(15)$ & $151.9(12)$ & 2016,1933 \\
\hline 9 & 260.8 & 95 & $\begin{array}{l}1.894(13) \\
1.922(11)\end{array}$ & $\begin{array}{c}149.0(10) \\
149.2(8)\end{array}$ & 2015,1942 \\
\hline 10 & 265.8 & 205 & $1.799(7)$ & $170.1(6)$ & $\begin{array}{c}2005,1988, \\
1916,1897\end{array}$ \\
\hline
\end{tabular}

a Measured in $\mathrm{CDCl}_{3}$ (ppm). ${ }^{\mathrm{b}}$ Measured in $\mathrm{CDCl}_{3}(\mathrm{~Hz}) .{ }^{\mathrm{c}}(\dot{\mathrm{A}}) \cdot{ }^{\mathrm{d}}\left({ }^{\circ}\right)$. e Measured in $\mathrm{CH}_{2} \mathrm{Cl}_{2}\left(\mathrm{~cm}^{-1}\right) .{ }^{f}$ Too broad or poor signal-to-noise to determine coupling constants.

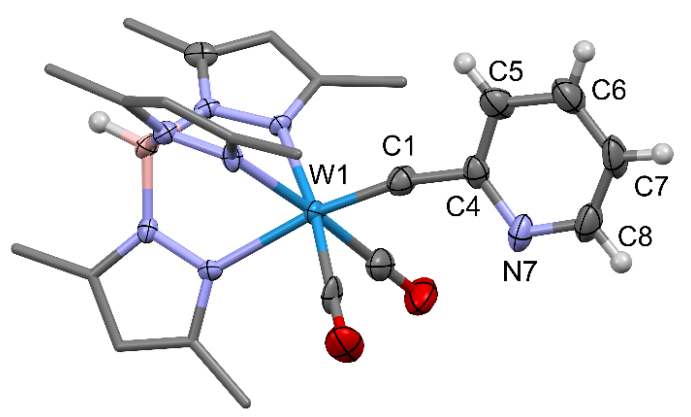

Figure 1. Molecular structure of $\mathbf{2}$ in a crystal of $\mathbf{2} \cdot \mathrm{CH}_{3} \mathrm{CN}(50 \%$ displacement ellipsoids, pyrazolyl groups simplified and solvent omitted for clarity). Selected distances $[\dot{A}]$ and angles [ ${ }^{\circ}$ ]: W1-C1 1.810(7), C1-C4 1.463(10), C4-C5 1.397(11), C5-C6 1.408(11), C6-C7 1.378(14), C7-C8 1.387(13), C8-N7 1.345(10), N7-C4 1.363(11), W1-C1-C4 167.8(7).

The NMR data for $\mathbf{2}$ and $\mathbf{3}$ are consistent with the wealth of those reported for carbynes ligated by poly(pyrazolyl)borates, ${ }^{4 c}$ featuring typical Tp* and pyridyl signatures. The carbyne carbon nuclei resonate at $\delta_{\mathrm{C}}=275.9\left({ }^{1} J_{\mathrm{CW}}=190\right)$ and $276.7\left({ }^{1} J_{\mathrm{CW}}=191\right.$
$\mathrm{Hz})$, respectively, close to that of the simple benzylidyne analogue $\left[\mathrm{W}(\equiv \mathrm{CPh})(\mathrm{CO})_{2}\left(\mathrm{Tp}^{*}\right)\right]\left(277.9 \mathrm{ppm},{ }^{1} \mathrm{~J}_{\mathrm{CW}}=187 \mathrm{~Hz}\right) .{ }^{13}$ The molecular structure of 2 (Figure 1 ) reveals that the $W \equiv C$ $(1.810$ (7) $\dot{A})$ and $C-C(1.463(10) \dot{A})$ distances associated with the carbyne unit are indicative of localised triple and single bonding, respectively.

The pyridyl nitrogens of both $\mathbf{2}$ and $\mathbf{3}$ are protonated by strong acids and on addition of $\mathrm{HBF}_{4} \cdot \mathrm{Et}_{2} \mathrm{O}$ the simple derivatives $\left[\mathrm{HNC}_{5} \mathrm{H}_{4}\left\{\mathrm{C} \equiv \mathrm{W}(\mathrm{CO})_{2}\left(\mathrm{Tp}^{*}\right)\right\}-2\right] \mathrm{BF}_{4} \quad[4] \mathrm{BF}_{4} \quad$ and $\left[\mathrm{HNC}_{5} \mathrm{H}_{3}\left\{\mathrm{C} \equiv \mathrm{W}(\mathrm{CO})_{2}\left(\mathrm{Tp}^{*}\right)\right\}_{2}-2,6\right] \mathrm{BF}_{4} \quad[5] \mathrm{BF}_{4}$, respectively, are prepared in good yields (Scheme 2). Protonation is readily reversed by treatment with bases such as $\mathrm{NEt}_{3}$ to return the precursors essentially quantitatively. Complex $[4]^{+}$appears empirically to be far more susceptible towards deprotonation and even washing a solid sample with diethyl ether or $n$ pentane begins to effect deprotonation. Accordingly, NMR spectroscopy was conducted in the presence of a slight excess of $\mathrm{HBF}_{4} \cdot \mathrm{Et}_{2} \mathrm{O}$. Both complexes $\mathbf{2}$ and $\mathbf{3}$ are irreversibly methylated by methyl trifluoromethanesulfonate to afford $\left[\mathrm{MeNC}_{5} \mathrm{H}_{4}\left\{\mathrm{C} \equiv \mathrm{W}(\mathrm{CO})_{2}\left(\mathrm{Tp}^{*}\right)\right\}-2\right] \mathrm{O}_{3} \mathrm{SCF}_{3} \quad\left[6 \mathrm{O}_{3} \mathrm{SCF}_{3} \quad\right.$ and $\left[\mathrm{MeNC}_{5} \mathrm{H}_{3}\left\{\mathrm{C} \equiv \mathrm{W}(\mathrm{CO})_{2}\left(\mathrm{Tp}^{*}\right)\right\}_{2}-2,6\right] \mathrm{O}_{3} \mathrm{SCF}_{3}[7] \mathrm{O}_{3} \mathrm{SCF}_{3}$, respectively, in equally good yields.

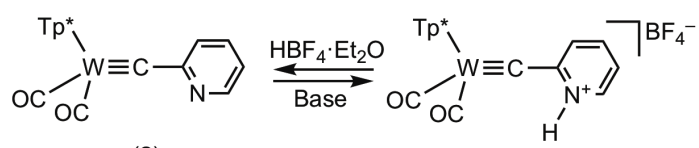

(2)

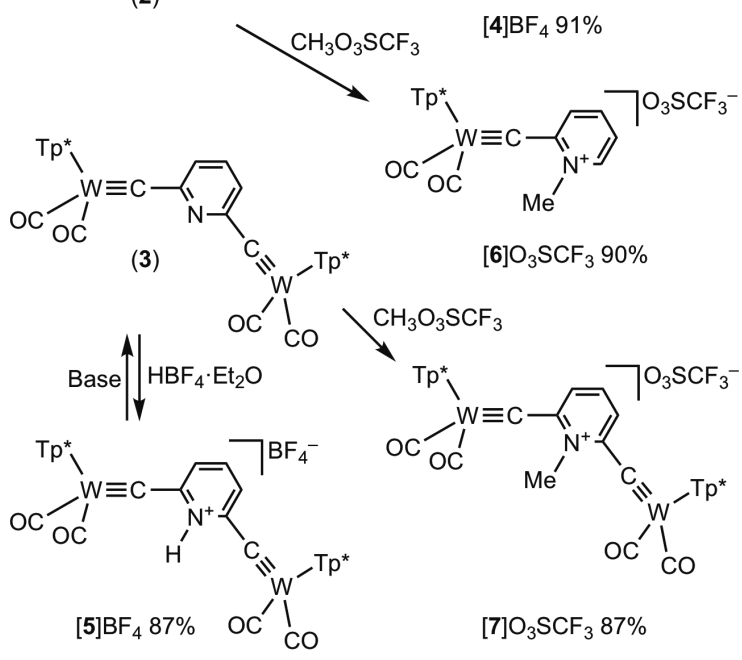

Scheme 2. Protonation and methylation reactions of pyridyl-substituted carbynes.

Protonation and methylation is accompanied by an increase of $c a 30 \mathrm{~cm}^{-1}$ in the carbonyl stretching frequencies in the infrared spectra of 4-7, consistent with a reduction in electron density at the tungsten metal centre compared to their precursors. The carbyne carbon resonances in the ${ }^{13} \mathrm{C}\left\{{ }^{1} \mathrm{H}\right\} \mathrm{NMR}$ spectra are shifted marginally (15-25 ppm) up-field. Together these data might suggest a contribution from canonical forms which locate the positive charge at tungsten (e.g., the vinylidene representation for $[6]^{+}$Chart $\left.2 b\right)$. Vinylidene complexes bearing nitrogen substituents are rare, being limited to the salts $\left[\mathrm{Ru}\left\{=\mathrm{C}=\mathrm{CPh}\left(\mathrm{N}=\mathrm{NC}_{6} \mathrm{H}_{3} \mathrm{Me}_{2}\right)\left(\mathrm{PPh}_{3}\right)_{2}\left(\eta-\mathrm{C}_{5} \mathrm{H}_{5}\right)\right] \mathrm{BF}_{4}{ }^{14}\right.$ and $\left[\mathrm{W}\left\{=\mathrm{C}=\mathrm{C}\left(\mathrm{NHCH}_{2} \mathrm{Ph}\right)_{2}\right\}(\mathrm{CO})_{2}\left(\mathrm{Tp}^{*}\right)\right] \mathrm{PF}_{6} \quad\left(\delta_{\mathrm{C}}=248.1 ; v_{\mathrm{CO}}=2020\right.$, $\left.1936 \mathrm{~cm}^{-1}\right)$ for which descriptions as an amidinium carbyne or 
$\mathrm{N}$-acyclic carbene-stabilised carbonium complex have been suggested. ${ }^{15}$ The latter draws analogy with phosphoniocarbynes ${ }^{16}$ and the pyridinium carbyne $\left[\mathrm{Mo}\left(\mathrm{CNC}_{5} \mathrm{H}_{4} \mathrm{NMe}_{2}-4\right)(\mathrm{CO})_{2}\left(\mathrm{Tp}^{*}\right)\right]^{+}\left(\delta_{\mathrm{C}}=214.1 ; v_{\mathrm{CO}}=2012,1929\right.$ $\left.\mathrm{cm}^{-1}, \mathrm{Mo} \equiv \mathrm{C}=1.807(4) \AA \AA\right) .{ }^{17}$ Whilst technically $[4]^{+}-[7]^{+}$provide the first examples of $N$-heterocyclic vinylidene complexes, the structural data collected for 5-7 (Figures S1-S2 in the ESI and Figure 2, respectively) do not, however, provide compelling support for this notion. The tungsten-carbon distances are not significantly elongated compared to $\mathbf{2}$, nor are the $\mathrm{C}_{\text {carbyne- }}$ $\mathrm{C}_{\text {pyridyl }}$ distances markedly shortened. Thus canonical forms (a) and (c) would each appear to provide useful contributions to the bonding description.

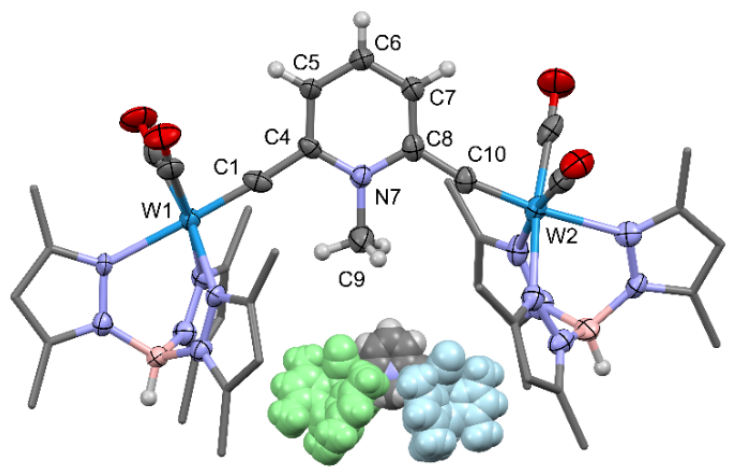

Figure 2. Molecular structure of the cation of [7] $]^{+}$in a crystal of $[7] \mathrm{O}_{3} \mathrm{SCF}_{3} \cdot\left(\mathrm{CHCl}_{3}\right)_{2.5}(50 \%$ displacement ellipsoids, one of two crystallographically independent molecules shown, pyrazolyl groups simplified and solvent and anion omitted for clarity). Selected distances $[\dot{A}]$ and angles [ $\left.{ }^{\circ}\right]$ : W1-C1 1.810(11), C1-C4 1.445(14), C8-C10 1.436(15), C10-W2 1.820(11), W1-C1-C4 175.3(9), W2-C10-C8 169.1(9). Inset: space-filling diagram with the ' $\left(\mathrm{Tp}^{*}\right)(\mathrm{CO})_{2} \mathrm{~W}^{\prime}$ units coloured green and blue.

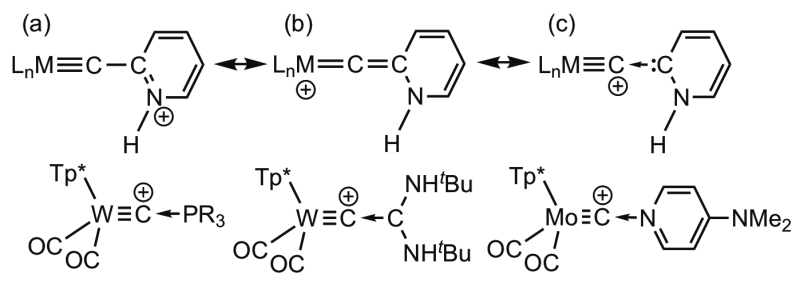

Chart 2. Canonical forms for a pyridinium carbyne complex [6]+ and related 'carbonium' species. (a) Carbyne; (b) N-heterocyclic vinylidene; (c) NHC-stablised carbonium.

Alternative sites of the (alkylidynyl)pyridines $\mathbf{2}$ and $\mathbf{3}$ are potentially available for metal coordination. Selected metal centres readily coordinate to the tungsten-carbon triple bond and treatment with $\left[\mathrm{AuCl}\left(\mathrm{SMe}_{2}\right)\right]$ (a reagent with demonstrated proclivity for $\mathrm{M} \equiv \mathrm{C}$ bonds ${ }^{5 b, 18}$ ) results in coordination of ' $\mathrm{AuCl}$ across the multiple bond. This occurs once for $\mathbf{2}$ to give the heterobimetallic derivative $\left[\mathrm{NC}_{5} \mathrm{H}_{3}\left\{\mathrm{CWAuCl}(\mathrm{CO})_{2}\left(\mathrm{Tp}^{*}\right)\right\}-2\right]$ (8) and twice for 3 to give the trimetallic complex $\left[\mathrm{NC}_{5} \mathrm{H}_{3}\left\{\mathrm{CWAuCl}(\mathrm{CO})_{2}\left(\mathrm{Tp}^{*}\right)\right\}_{2}-2,6\right]$ (9) (Scheme 3). Coordination of the gold $(\mathrm{I})$ fragments results in a minor (ca $10 \mathrm{ppm}$ ) up-field shift in the carbyne carbon resonance in the ${ }^{13} \mathrm{C}\left\{{ }^{1} \mathrm{H}\right\} N M R$ spectra and a halving of the ${ }^{1} J_{\mathrm{CW}}$ coupling constants, consistent with a reduction in the $s$-character of the tungsten-carbon bonds. The geometries of both complexes have been structurally authenticated (Figures S3 and S4 in the

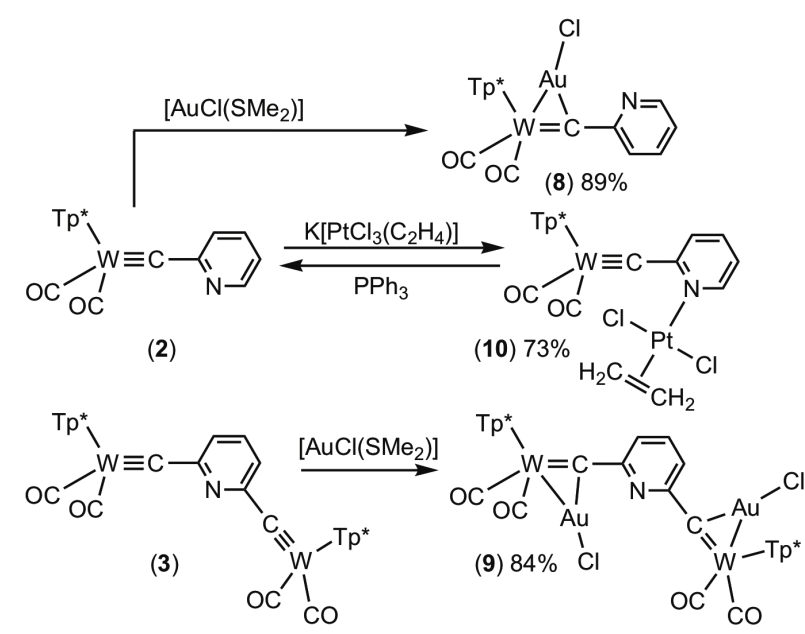

Scheme 3. Addition of gold(I) and platinum(II) reagents to complexes $\mathbf{2}$ and $\mathbf{3}$.

ESI). The two gold units in 9 orient away from each other and do not support an aurophilic Au $\cdots \mathrm{Au}$ interaction ${ }^{19}$ such as those observed previously in carbynes bridged by single phosphorus ${ }^{16 b}$ or tellurium ${ }^{20}$ atoms; presumably they are held too remotely for this to occur.

The pyridyl nitrogen is also capable of coordinating to metal centres and on treatment of 2 with $\mathrm{K}\left[\mathrm{PtCl}_{3}\left(\mathrm{C}_{2} \mathrm{H}_{4}\right)\right] \cdot \mathrm{H}_{2} \mathrm{O}$ (Zeise's salt), a chloride ligand on platinum is displaced and the heterobimetallic complex $\left[\mathrm{Cl}_{2}(\eta\right.$ $\left.\left.\mathrm{C}_{2} \mathrm{H}_{4}\right) \mathrm{PtNC}_{5} \mathrm{H}_{4}\left\{\mathrm{C} \equiv \mathrm{W}(\mathrm{CO})_{2}\left(\mathrm{Tp}^{*}\right)\right\}-2\right](\mathbf{1 0})$ is formed. In this complex the otherwise typically labile ethene ligand is retained and is located trans to the pyridyl nitrogen. The ${ }^{1} \mathrm{H}$ and ${ }^{13} \mathrm{C}\left\{{ }^{1} \mathrm{H}\right\} \mathrm{NMR}$ spectra are not profoundly influenced by $\mathrm{Pt}(\mathrm{II})$ coordination beyond the appearance new resonances at $\delta_{\mathrm{H}}=4.63$ and $\delta_{\mathrm{C}}=$ 75.9 in their respective spectra due to the platinum-bound ethene $\mathrm{H}_{2} \mathrm{C}=\mathrm{CH}_{2}$ ligand. Their observation as singlets devoid of observable ${ }^{195} \mathrm{Pt}$ satellites is most likely a product of a rapid fluxional process; the dynamics of $\mathrm{Pt}(\mathrm{II})$ olefin complexes is welldocumented. ${ }^{21}$ The carbyne carbon nuclei in $\mathbf{1 0}$ resonate ca 10 ppm further up-field upon Pt(II) coordination compared to 2 and the platinum centre gives rise to a broad resonance at $\delta_{\mathrm{Pt}}=$ $-2864 \mathrm{ppm}$ in the ${ }^{195} \mathrm{Pt}$ NMR spectrum.

The molecular structure of $\mathbf{1 0}$ (Figure 3 ) provides further confirmation of pyridyl $\mathrm{N}$-coordination to $\mathrm{Pt}(\mathrm{II})$ and retention of the ethene ligand. The $\mathrm{W} \equiv \mathrm{C}$ and $\mathrm{C} 1-\mathrm{C} 4$ distances are crystallographically identical to those of the precursor 2, indicating that metal coordination in this site has at best a very minor influence on the structure of the alkylidyne motif. The ethylene ligand aligns approximately with the $W \equiv C$ axis, between the two carbonyl ligands on $W$ such that the two ends of the olefin are inequivalent in the solid state. NMR spectroscopy confirms that this conformation is not rigidly maintained in solution. Structural parameters associated with the platinum fragment are in good agreement with the small number of other reported $\left[\mathrm{Pt} "\left(\mathrm{C}_{2} \mathrm{H}_{4}\right) \mathrm{L}_{3}\right]$ complexes. ${ }^{22}$ The pyridyl-platinum interaction is rather labile and addition of one equivalent triphenylphosphine rapidly results in displacement and quantitative recovery of $\mathbf{2}$. Attempts to prepare derivatives with two equivalents of $\mathbf{2}$ coordinated to 


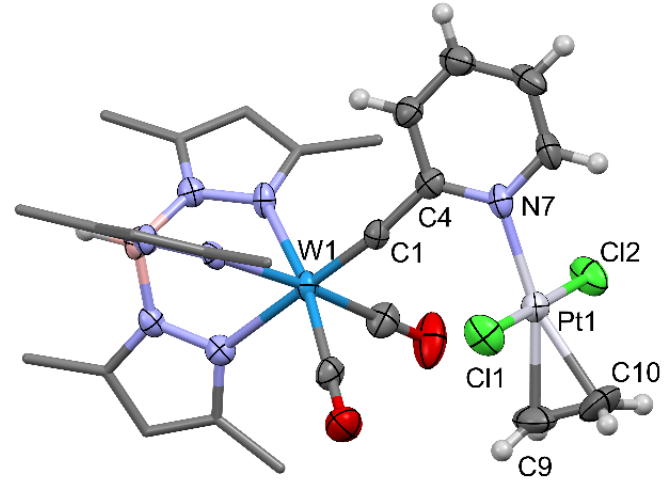

Figure 3. Molecular structure of $\mathbf{1 0}$ (50\% displacement ellipsoids, pyrazolyl groups simplified for clarity). Selected distances [Aं] and angles [ $\left.{ }^{\circ}\right]$ : W1-C1 1.799(7), C1-C4 1.452(10), N7-Pt1 2.067(6), Pt1-C9 2.144(9), Pt1-C10 2.142(9), Pt1-Cl1 2.294(2), Pt1Cl2 2.294(2), W1-C1-C4 170.1(6), N7-Pt1-C9 160.5(4), N7-Pt1-C10 162.1(4), N7-Pt1Cl1 89.07(17), N7-Pt1-Cl2 90.05(17).

platinum by treatment of $\mathbf{2}$ with half an equivalent of $\mathrm{K}\left[\mathrm{PtCl}_{3}\left(\mathrm{C}_{2} \mathrm{H}_{4}\right)\right] \cdot \mathrm{H}_{2} \mathrm{O}\left(40{ }^{\circ} \mathrm{C}, 1: 1 \mathrm{CH}_{2} \mathrm{Cl}_{2}\right.$ :ethanol), provided an orange-brown solid, however the ${ }^{1} \mathrm{H}$ NMR spectroscopic data was exceptionally broadened, even down to $-50{ }^{\circ} \mathrm{C}$, and single crystals proved elusive. A yellow-brown product was also obtained when $\mathbf{3}$ was treated with one equivalent of Zeise's salt (RT, 1:1 $\mathrm{CH}_{2} \mathrm{Cl}_{2}$ /ethanol) but this compound also manifested ${ }^{1} \mathrm{H}$ NMR broadening and aversion to crystallisation. Thus, while initially promising, unequivocal characterisation of these two products remains an ongoing challenge. In both cases, rapid fluxional processes are likely to be occurring. In the latter case, the steric bulk about the pyridyl nitrogen (see inset, Figure 2) might contribute to the increase in lability compared to 10.

In conclusion, the synthesis of 2-pyridylcarbynes has been achieved via the $\mathrm{Pd} / \mathrm{Au}^{\prime}$-mediated coupling of stannyl carbynes with 2-bromopyridine or 2,6-dibromopyridine. This strategy promises considerable generality for installing a wide range of previously inaccessible, functional substituents on metal carbynes. These may, in turn, ultimately find use in a range of applications by virtue of their potentially 'switchable' influence on electronic, optical or physical properties as exemplified here by reversible protonation or metal coordination, including the synthesis of the first examples of $N$-heterocyclic vinylidenes. The scope and properties of new complexes prepared by this strategy are the subject of ongoing research on which we will report subsequently.

\section{Acknowledgements}

We gratefully acknowledge the Australian Research Council (DP170102695 and DP190100723) for funding. The authors declare no conflicts of interest.

\section{Notes and references}

1 (a) E. O. Fischer, G. Kreis, C. G. Kreiter, J. Müller, G. Huttner and H. Lorenz, Angew. Chem. Int. Ed. Engl., 1973, 12, 564-565.
2 (a) L. J. Guggenberger and R. R. Schrock, J. Am. Chem. Soc., 1975, 97, 2935-2935. (b) R. R. Schrock, Chem. Rev., 2002, 102, 145-180. (c) R. R. Schrock, Chem. Commun., 2005, 2773-2777.

3 M. L. Listemann and R. R. Schrock, Organometallics, $1985,4,74-83$.

4 (a) C. Shi and G. Jia, Coord. Chem. Rev., 2013, 257, 666-701. (b) L. M. Caldwell, Adv. Organomet. Chem., 2008, 56, 1-94.

5 (a) A. F. Hill and R. A. Manzano, Angew. Chem., Int. Ed., 2019, 58, 15354-15357. (b) A. R. Delaney, B. J. Frogley and A. F. Hill, Dalton Trans., 2019, 48, 13674-13684. (c) R. D. Dewhurst, A. F. Hill and A. C. Willis, Organometallics, 2005, 24, 13, 30433046. (d) R. D. Dewhurst, A. F. Hill and M. K. Smith, Angew. Chem., Int. Ed., 2004, 43, 476-478. (e) A. F. Hill and R. A. Manzano, Angew. Chem., Int. Ed., 2019, 58, 7357-7360.

6 (a) D. C. Milan, A. Vezzoli, I. J. Planje and P. J. Low, Dalton Trans., 2018, 47, 14125-14138. (b) Y. Tanaka, M. Kiguchi and M. Akita, Chem. Eur. J., 2017, 23, 4741-4749

7 (a) T. P. Pollagi, S. J. Geib and M. D. Hopkins, J. Am. Chem. Soc., 1994, 116, 6051-6052. (b) D. B. Moravec and M. D. Hopkins, J. Phys. Chem., A, 2013, 117, 1744-1755.

8 B. J. Frogley and A. F. Hill, Chem. Commun., 2019, 55, 1240012403.

9 (a) E. S. Borren, A. F. Hill, R. Shang, M. Sharma and A. C. Willis, J. Am. Chem. Soc., 2013, 135, 4942-4945. (b) A. Reinholdt, J. Bendix, A. F. Hill and R. A. Manzano, Dalton Trans., 2018, 47, 14893-14896.

10 R. L. Cordiner, A. F. Hill and J. Wagler, Organometallics, 2008, 27, 5177-5179.

11 (a) L. S. Liebeskind and R. W. Fengl, J.. Org. Chem., 1990, 55 5359-5364; (b) S. P. H. Mee, V. Lee and J. E. Baldwin, Angew. Chem. Int. Ed., 2004, 43, 1132-1136.

12 J. del Pozo, D. Carrasco, M. H. Pérez-Temprano, M. GarcíaMelchor, R. Álvarez, J. A. Casares and P. Espinet, Angew. Chem. Int. Ed., 2013, 52, 2189-2193.

13 K. C. Stone, G. M. Jamison, P. S. White and J. L. Templeton, Inorg. Chim. Acta, 2002, 330, 161-172.

14 I. R. Whittall, M. P. Cifuentes, M. J. Costigan, M. G. Humphrey, S. C. Goh, B. W. Skelton and A. H. White J. Organomet. Chem., 1994, 471, 193-199.

15 K. Helmdach, J. Ruger, A. Villinger and W. W. Seidel Chem. Commun., 2016, 52, 2616-2619.

16 (a) G. M. Jamison, P. S. White and J. L. Templeton, Organometallics, 1991, 10, 1954-1959. (b) A. L. Colebatch and A. F. Hill, Dalton Trans., 2017, 46, 4355-4365. (c) A. L. Colebatch, A. F. Hill and M. Sharma, Organometallics, 2015, 34, 2165-2182.

17 R. L. Cordiner, A. F. Hill and J. Wagler, Organometallics, 2008, 27, 4532-4540.

18 (a) G. A. Carriedo, J. C. Jeffery and F. G. A. Stone, J. Chem. Soc., Dalton Trans., 1984, 1597-1603. (b) G. A. Carriedo, V. Riera, G. Sánchez and X. Solans, J. Chem. Soc., Dalton Trans., 1988, 1957-1962. (c) C. E. Strasser, S. Cronje and H. G. Raubenheimer, New J. Chem., 2010, 34, 458-469; (d) A. L. Colebatch and A. F. Hill, Dalton Trans., 2017, 46, 4355-4365; (e) B. J. Frogley, A. F. Hill and C. S. Onn, Dalton Trans, 2019, 48, 11715-11723; (f) B. J. Frogley and A. F. Hill, Angew. Chem. Int. Ed. Engl., 2019, 58, 8044-8048.

19 H. Schmidbaur and A. Schier, Chem. Soc. Rev., 2012, 41, 370412.

20 B. J. Frogley, A. F. Hill, R. A. Manzano and M. Sharma, Chem. Commun., 2018, 54, 1702-1705.

21 T. A. Albright, R. Hoffmann, J. C. Thibeault and D. L. Thorn, J. Am. Chem. Soc., 1979, 101, 3801-3812.

22 (a) W. C. Deese, D. A. Johnson and A. W. Cordes, Inorg. Chem., 1981, 20, 1519-1522. (b) N. Carr, L. Mole, A. G. Orpen and J. L. Spencer, J. Chem. Soc., Dalton Trans., 1992, 2653-2662. (c) V. G. Albano, C. Castellari, V. De Felice, A. Panunzi and F. Ruffo, J. Organomet. Chem., 1992, 425, 177-188. 
